\title{
INDEXAÇÃO SOCIAL NO SKOOB: A DESCRIÇÃO DO LIVRO 'O MUNDO DE SOFIA' A PARTIR DE TAGS E RESENHAS
}

\author{
INDIZACIÓN SOCIAL EN SKOOB: LA \\ DESCRIPCIÓN DEL LIBRO 'EL MUNDO DE \\ SOFÍA’ A PARTIR DE TAGS Y RESEÑAS
}

\author{
Raquel Juliana Prado Leite de Sousa* \\ Marina Benetti**
}

\begin{abstract}
RESUMO
Introdução: O Skoob é uma rede social brasileira baseada na troca de informações sobre livros e revistas, que permite ao usuário, ou skoobers, a inserção de tags para a organização de suas estantes pessoais, bem como para o compartilhamento público de descrição dos recursos. A análise da etiquetagem de livros literários é um indicativo do comportamento dos leitores frente à atividade de indexação social.

Objetivo: Explorar a indexação social realizada no Skoob, a fim de analisar os conceitos utilizados em tags, comparando-os aos conceitos presentes em resenhas escritas pelos leitores.

Metodologia: Foi selecionado o livro 'O mundo de Sofia: romance da história da filosofia', de Jostein Gaarder. Primeiramente, levantou-se a discrepância das tags mais populares atribuídas ao livro. Em seguida, através da Análise de Conteúdo com abordagem qualitativa, foram analisadas 30 resenhas, a fim de encontrar os conceitos presentes na apreciação crítica dos leitores. Por fim, foi feita uma comparação entre os conceitos das tags e das resenhas.

Resultados: Houve discrepância entre as tags no que se refere ao número (singular e plural). Os conceitos levantados nas resenhas foram agrupados em três categorias: a) Assunto; b) Gênero Textual; e c) Juízos de Valor. Os conceitos presentes nas tags e nas resenhas, de um modo geral, foram diferentes.

Conclusão: Foi possível, através da análise das resenhas, aprofundar a compreensão de alguns conceitos presentes nas tags. Entretanto, dentre os conceitos mais citados nas resenhas, apenas 'filosofia' e 'mistério' estão presentes entre as tags mais populares.
\end{abstract}

Palavras-chave: Folksonomias. Literatura. Redes sociais. Análise de conteúdo.

* Doutoranda em Educação pela Universidade Federal de São Carlos (UFSCAR). Email: quel.leite@gmail.com

** Graduada em Biblioteconomia e Ciência da Informação pela Universidade Federal de São Carlos (UFSCAR). E-mail: marinabenetti93@gmail.com 


\section{INTRODUÇÃO}

A mudança de paradigma proporcionada pela Web 2.0 transpôs o modelo de passividade do leitor, que antes devia se contentar em apenas receber o conteúdo já pronto e organizado, e cedeu espaço a uma interação cada vez maior, pela invenção de ferramentas mais democráticas não apenas de criação, mas também de organização de recursos.

As relações horizontalizadas na Web social têm promovido discussões acerca da necessidade e eficácia da utilização de Linguagens Documentárias (LDs). Entretanto, cremos que 0 empoderamento do usuário ao indexar o conteúdo na Web social não significa o fim das LDs, nem da atividade de indexação dentro da Biblioteconomia; ao contrário, se bem aproveitado, pode significar uma maior aproximação com o universo do leitor, promovendo estudos de usos e usuários onde é possível observar o modo como eles agem ao descrever os recursos, e não somente a forma como buscam a informação. Partindo dessa afirmação, temos na folksonomia uma fonte exploratória de estudos do comportamento do usuário enquanto organizador da informação.

Entretanto, como ressalta Santos (2013), é impossível estudar todos os perfis de usuários, sendo necessário agrupá-los de acordo com suas similaridades, classificando-os em grupos. Dessa forma, selecionamos para esta análise um grupo de usuários do Skoob, rede social baseada no compartilhamento de informações sobre literatura, cuja similaridade é o interesse pelo livro 'O Mundo de Sofia', de Jostein Gaarder. O objetivo é explorar a indexação social realizada por esses usuários para a descrição de conteúdo de livros de literatura, comparando os conceitos presentes nas tags mais populares aos conceitos citados nas resenhas sobre o livro.

Um dos grandes desafios dos bibliotecários, quando se trata de representar o conteúdo dos documentos, é a descrição de assuntos de 
textos literários. Estudos como o de Guimarães, Moraes e Guarido (2007) e Moraes (2012) discutem a complexidade da análise documentária de textos narrativos de ficção, os quais, obviamente, carecem de um tratamento diferenciado do texto científico.

A subjetividade inerente ao texto literário, cujo sentido foge da significação única, reflete-se na análise documentária. Partimos do pressuposto que o estudo da relação dos leitores com o texto de ficção pode ser um bom indicador a nortear a leitura documentária desse gênero textual, bem como para a elaboração ou validação de Linguagens Documentárias.

\section{INDEXAÇÃO SOCIAL}

O termo folksonomy, traduzido para o português como folksonomia, foi cunhado por Thomas Vander Wal no ano de 2004, a fim de descrever o ato de atribuir tags, ou etiquetas, a recursos presentes na Web 2.0.

Vander Wal (2005) critica a quantidade de trabalhos acadêmicos que tem citado a definição da Wikipédia para o termo, afirmando que ela se tornou completamente descolada do que ele entende por folksonomia, pois essa não é colaborativa, não significa colocar as coisas em categorias e nem está relacionada à taxonomia, pois é, na verdade, sua antítese. O autor então define folksonomia como o resultado da marcação de informações e objetos (qualquer coisa com um endereço eletrônico) feita livremente pela pessoa que consome a informação para sua própria recuperação, a qual é realizada em um ambiente social, ou seja, compartilhado e aberto a outros usuários.

Vander Wal (2005) explica que há um grande valor derivado dessa marcação pessoal se a virmos como uma atividade coletiva embasada em três pontos de dados: 1) a pessoa que faz a marcação; 2) o objeto que está sendo marcado; e 3) a tag que está sendo utilizada. A utilização de apenas um dos pontos prejudica a recuperação da 
informação, mas a utilização das três camadas permite que se usem dois dos elementos para encontrar o terceiro, podendo remeter para alguém que tenha os mesmos interesses e faça uso do mesmo vocabulário que você, o que se torna um filtro para a informação.

Ao comparar folksonomia e taxonomia, Vander Wal (2013) diz que a primeira pode ser usada como base para a segunda, entretanto, falta-lhe uma estrutura como a da taxonomia. O autor afirma que a folksonomia pode ser usada para validar taxonomias, caso os termos de etiquetagem apontem para o mesmo objeto, e também para identificar lacunas, em casos onde os termos não apareçam na taxonomia.

Em se tratando de folksonomia, deparamo-nos com divergências de duas ordens: 1) quanto à conceituação; e 2) quanto à nomenclatura.

Ao estudar a conceituação do termo folksonomia, Catarino e Baptista (2009) dividiram em dois grupos os teóricos que se debruçam sobre o assunto: 1) os que a veem como um produto, sendo o resultado de um processo; e 2) os que a enxergam como o próprio processo, funcionando como um sistema, uma metodologia ou abordagem.

As autoras também ressaltaram a variedade de termos utilizados para nomear o ato de atribuir tags: a) classificação social ou distribuída; b) etnoclassificação; c) social bookmarking; d) tagging; e) tagging systems; f) social tagging; g) social tagging systems; h) collaborative tagging systems; i) social classification; j) bookmarking; k) social bookmarking; I) social bookmarking manager, m) social ontologies; e n) taxonomia dinâmica.

Encontramos, também, as expressões thesaurus social, citado por Gouvêa e Loh (2007), que ressaltam seu baixo uso em trabalhos científicos, e indexação social, usada por Guedes e Dias (2010).

Para este trabalho, foi adotada a expressão indexação social descrita por Guedes e Dias (2010), pela aproximação com o conceito de indexação para a Biblioteconomia, tendo em seu cerne a concepção da indexação orientada pelo usuário, além do caráter democrático de socialização do conhecimento gerado nesse processo. 
Uma etiqueta (tag) criada por um usuário pode ser utilizada por todos os outros, assim como um item classificado por um usuário também é livre para ser classificado por quem quiser, criando um ambiente favorável ao desenvolvimento do conhecimento coletivo. Esse conhecimento emerge de um sistema governado por forças bottom-up, isto é, da periferia para o centro (GUEDES; DIAS, 2010, p. 47).

Com base nas considerações de Gouvêa e Loh (2007), podemos citar vantagens e desvantagens da indexação social. Vantagens: a) recuperação e descoberta de conhecimento; b) compartilhamento de conhecimento e de modos de organizá-lo; c) intelectualmente mais acessível em decorrência da associação de classes e, consequentemente, de conteúdos; d) alternativa à websemântica; e) definição de conteúdos secundários, não apenas dos centrais; f) descentralização, com estrutura menos rígida e mais flexível; e g) facilidade de uso. Já as desvantagens são: a) incoerência entre as tags e os conceitos que essas pretendem descrever; b) erros de grafia, discrepância de significados e inadequação gramatical; e c) problemas nos usos das tags genéricas e específicas, pela associação com conceitos coletivos ou meramente individualistas.

Catarino e Baptista (2009) também levantam prós e contras da utilização de tags. Como vantagens, tocam em questões como: a) compartilhamento de etiquetas que podem ser usadas por outros usuários; b) formação automática de comunidades com interesses mútuos; e c) rompimento com regras preestabelecidas, possibilitando liberdade de expressar sua visão do assunto. Como desvantagens citam: a) falta de controle do vocabulário; b) pouca precisão na recuperação da informação pela discrepância de sentido atribuído às tags; c) imprecisão de termos e inconsistência no uso de sinônimos, homônimos, gênero, número, etc.

Vale ressaltar que, conforme explica Santos (2013), as etiquetas não variam apenas pela diversidade de expressão permitida pela linguagem, mas também em decorrência dos inúmeros significados que 
podem ser atribuídos ao documento pelos diferentes indivíduos e em diversos contextos. Entretanto, devemos nos atentar para o fato de que o usuário, ao buscar um documento, também o identifica conforme uma significação particular.

Para Santos (2013), a motivação que leva o usuário a atribuir etiquetas aos recursos digitais pode ser classificada em organizacional ou social: a primeira diz respeito à intenção de organizar os próprios dados, ou seja, em benefício próprio, já a segunda se refere à intenção de compartilhar seus dados, colaborando com os demais usuários. O estudo do primeiro se torna mais subjetivo, uma vez que nem sempre se tem acesso às tags de uso pessoal, além da dificuldade de compreender as idiossincrasias de cada leitor na atribuição de significados ou de relações entre a tag e o conteúdo que pretende descrever. No segundo caso, o estudo do conjunto de descrições criadas e compartilhadas pelos leitores, com o propósito claro de socializar a descrição de um recurso, torna-se um bom indicador de como eles não apenas descrevem os recursos, mas também de como fazem para torná-lo mais acessível. Dessa forma, a etiquetagem social foi escolhida para esta pesquisa, de modo a explorar os conceitos presentes nas tags compartilhadas por leitores de literatura.

\section{PROCEDIMENTOS METODOLÓGICOS}

Para o presente trabalho, foi utilizada a Análise de Conteúdo (AC) com abordagem qualitativa. De acordo com Bardin (1977), a AC se divide em três fases: a) pré-análise; b) exploração do material e tratamento de resultados; e c) inferências e interpretação. Na primeira fase se dá a concepção da pesquisa, pela escolha dos documentos a serem analisados, levantamento de hipóteses e objetivos e criação de categorias de análise. A segunda fase se baseia na análise para levantamentos de dados, já na terceira fase se dão o tratamento e a apreciação crítica desses dados. Ressalte-se que tais etapas podem 
aparecer consecutivamente ou serem feitas concomitantemente, pois estão intimamente ligadas (BARDIN, 1977).

A escolha dos corpora, ou seja, a formação de um conjunto de textos que será sistematicamente analisado, foi dada a priori, uma vez que se possuía um determinado material que já se desejava analisar.

Para a análise foi escolhido o Skoob, rede social para troca de informações sobre livros e revistas, pela possibilidade de trabalhar com a etiquetagem de um recurso tradicional para a Biblioteconomia: os livros. Foi selecionada a obra 'O mundo de Sofia: romance da história da filosofia', do escritor norueguês Jostein Gaarder. Ressalte-se que foi utilizada a obra cadastrada em língua portuguesa.

Primeiramente foram levantadas as tags mais populares atribuídas ao livro; frente a elas, procuraram-se possíveis inconsistências presentes na sua grafia.

Em seguida, foram selecionadas as 30 últimas resenhas publicadas pelos leitores até a data de 12 de maio de 2013. A partir do fichamento das resenhas, foram então realizados 0 inventário (isolamento dos elementos) e a classificação (organização de elementos), o que deu o embasamento para a formação de categorias de análise, tendo sido utilizada a categorização 'por acervo', método que consiste em definir as categorias de análise a posteriori. Esse trabalho foi importante para comparar as tags citadas como mais populares aos conceitos presentes nos textos dos leitores, a fim de confrontar as duas atividades feitas pelos usuários: a etiquetagem e a recensão. Ressaltese que foram analisadas apenas as resenhas, desconsiderando-se seus comentários.

\section{SKOOB}

O Skoob é uma rede social online brasileira alimentada exclusivamente por leitores, ou skoobers, que indicam, comentam e avaliam livros e revistas, compartilhando opiniões críticas e sugestões. 
Como o próprio site define "o skoob é o local onde você diz o que está lendo, o que já leu e o que ainda vai ler, seus amigos fazem o mesmo e assim, todos compartilham suas opiniões e críticas" (SKOOB, 2013).

Criado em janeiro de 2009 pelo desenvolvedor Lindenberg Moreira, seu nome não foi escolhido por acaso: SKOOB lendo ao contrário é BOOKS, uma palavra inglesa que, traduzindo para o português, significa 'livros'. Talvez não por acaso seja o homônimo de um sebo londrino, Skoob books.

Essa comunidade de leitura, que possui mais de 300 mil leitores, como informado pela própria descrição do Skoob, foi concebida a partir da intenção de responder à pergunta apresentada pela música 'Good people' de Jack Johnson que diz: 'Where'd all the good people go?' (em português 'Para onde todas as pessoas boas foram?'), afirmando que as pessoas boas se encontram nessa rede (SKOOB, 2013).

O Skoob funciona à semelhança de outras redes sociais, pois permite adicionar amigos através dos perfis criados, bem como criar grupos e interagir com os outros skoobers. Para usá-lo, o leitor deve, primeiramente, cadastrar-se criando uma conta ou fazendo o acesso através do Facebook. Logo após, para começar a interagir, deve inserir livros na sua estante, marcando se já os leu, está lendo, vai ler, está relendo ou abandonou a leitura. Uma vez na estante do leitor, é possível avaliar o livro, marcando-o com uma a cinco estrelas, bem como assinalar outras opções como favorito, emprestei, desejado, tenho, etc.

O leitor pode cadastrar obras no Skoob, que também permite a inserção de revistas, HQs e mangás. Quando as obras cadastradas possuem mais de uma edição, apenas uma é indicada como a edição principal, ou seja, aquela em que os leitores vão inserir tags, resenhas, debates, avaliação, etc., o que garante que todos os comentários sejam postados em um único lugar, evitando dispersão. Quando há duplicatas, o leitor pode avisar o Skoob simplesmente clicando no link Duplicada?, que aparece sempre abaixo da cada obra cadastrada. 
Toda a interação entre usuários dentro do Skoob gira em torno das publicações, assim, o assunto central da comunidade é sempre a literatura.

Uma das ferramentas disponíveis aos leitores é a inserção de tags. Existem dois tipos de tag no Skoob: as tags de 'estante', que são etiquetas criadas apenas para ajudar a organizar os livros na estante do leitor, sendo que essas não são compartilhadas com os demais skoobers, e as tags 'públicas', que auxiliam na descrição e busca das obras, sendo compartilhadas com todos os usuários.

Dessa forma, caso o livro seja etiquetado como 'presente de natal 2003' na categoria de 'estante', ao se digitar 'presente de natal 2003' na busca geral, ele não será recuperado, pois se trata de uma indexação para uma estante específica. Já ao fazer uma busca com a palavra 'filosofia' no campo geral, serão apresentados todos os livros que foram indexados com tag 'pública' filosofia.

Além da inserção de tags, os leitores podem postar resenhas, com suas opiniões sobre as leituras. As resenhas podem ser avaliadas pelos skoobers com as opções 'gostei' e 'não gostei', bem como podem ser comentadas livremente. Isso permite o entrelaçamento de um diálogo aberto entre os leitores. É possível ver as resenhas organizadas por data, das mais recentes às mais antigas, pelas mais comentadas e pelas mais marcadas com a opção gostei.

Um dos cuidados que o Skoob tem é o de evitar que certas descrições reveladoras das obras, conhecidas como spoiler, não sejam lidas, uma vez que tais detalhes, como a revelação do desfecho de uma narrativa, por exemplo, podem desestimular a leitura. Assim, quando há spoiler na resenha, o usuário deve marcar essa opção antes de postar seu texto. No local da sua resenha, então, aparecerá a palavra spoiler em vermelho, sendo que os leitores interessados em lê-la precisam apenas clicar na palavra para acessar o texto.

Apesar de dar ao leitor a possibilidade de utilizar diversos recursos, o Skoob é restrito quanto à visualização das tags dos livros, 
pois não permite ver as etiquetas mais populares da rede social como um todo e não trabalha com nuvem de tags, impedindo que o usuário saiba quais são os assuntos mais marcados na rede e em cada um dos livros. Quando se acessa determinado livro, as tags mais populares desse são expostas como uma simples listagem.

Além de toda a interação entre leitores, o skoober pode criar o perfil plus, que permite a troca de livros. O Skoob ainda conta com a Livraria Skoob, sendo que em cada obra cadastrada há o link comprar, que remete diretamente a esse site de vendas.

\section{RESULTADOS}

Segundo Santos (2013, p. 101), "não é sempre que as etiquetas são atribuídas com o intuito de terem audiência, ou seja, que o usuário adiciona uma etiqueta, tornando-a pública. Por vezes, o que se quer é organizar os próprios dados". Dessa forma, partimos da hipótese de que, no Skoob, as tags são utilizadas a fim de contribuir para que os demais usuários possam recuperar o recurso desejado, bem como para reforçar o juízo de valor atribuído ao livro, servindo como validação e imposição da apreciação pessoal do leitor, que visa a convencer outros leitores do seu ponto de vista, influenciando-os na sua apreciação.

Um importante indicativo de juízo de valor atribuído ao livro é sua avaliação geral, pois nos dá pistas sobre as apreciações positivas e negativas feitas pelos leitores. O livro foi avaliado pelos skoobers com a nota média de 4 estrelas (sendo 5 o máximo de estrelas permitidas), como visto na figura 1. Dos 18.822 leitores que avaliaram o livro, $72 \%$ atribuíram nota superior à nota média. 
Figura 1 - Estatísticas de avaliação do livro pelos skoobers em 24 de maio de 2013.

\section{Estatísticas}

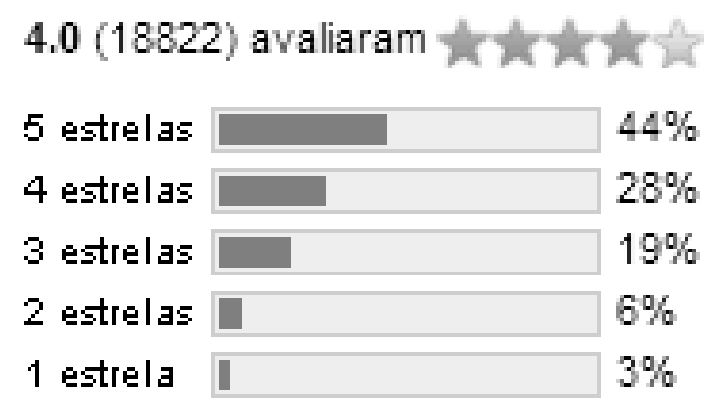

Fonte: Skoob (2013).

Entretanto, ressalte-se que esse dado, sozinho, não permite afirmar que o livro é apreciado pela maioria dos skoobers, uma vez que a avaliação do livro é opcional. Além disso, os leitores podem modificar sua avaliação a qualquer momento, bastando clicar novamente na quantidade de estrelas que deseja atribuir para gravar uma nova nota.

À época da pesquisa, o livro estava presente na estante de 58.152 leitores. Esse total representa a soma de leitores que aparecem na figura 2, sendo que 34.976 haviam lido o livro, 3.182 estavam lendo, 12.622 iriam ler, 351 estavam relendo e 7.021 tinham abandonado a leitura.

Figura 2 - Número de leitores de 'O mundo de Sofia' em 24 de maio de 2013.

\begin{tabular}{|c|c|c|c|c|}
\hline 4.0 18822 avaliaçôes & $\begin{array}{l}34976 \\
\text { leram }\end{array}$ & $\begin{array}{l}3182 \\
\text { lendo }\end{array}$ & $\begin{array}{l}12622 \\
\text { văo ler }\end{array}$ & $\begin{array}{l}351 \\
\text { relendo }\end{array}$ \\
\hline
\end{tabular}

\section{O Mundo de Sofia}

Romance da História da Filosofia

f Curtir 965

Fonte: Skoob (2013).

Só é permitido ao skoober atribuir uma nota ao livro se ele o insere em sua estante; entretanto, não é necessário que ele tenha 
Raquel Juliana Prado Leite de Sousa, Marina Benetti Correio Indexação social no Skoob: a descrição do livro "O Mundo de Sofia" a partir de tags e resenhas

terminado a leitura, podendo avaliar a obra mesmo que a esteja lendo, pretende lê-la, abandonou a leitura ou nunca a tenha iniciado. Sendo assim, frente ao total de leitores que inseriram o referido livro em sua estante, apenas $32,36 \%$ atribuíram uma nota, não sendo possível saber quantos desses realmente o leram. Ressalte-se, também, que o livro teve 7021 abandonos, o que representa $12 \%$ do total de leitores.

$\mathrm{Na}$ figura 3 aparecem as tags mais populares atribuídas ao livro. Note-se que o Skoob apresenta apenas uma lista, sem utilizar nuvem de tags, ou seja, sem marcar visualmente as etiquetas que ocorrem com mais frequência. Assim, dentre as tags populares para o livro escolhido, não é possível saber quais são mais utilizadas ou classificá-las por ordem de ocorrência.

Figura 3 - Tags mais populares atribuídas ao livro em 24 de maio de 2013.

\section{tags populares}

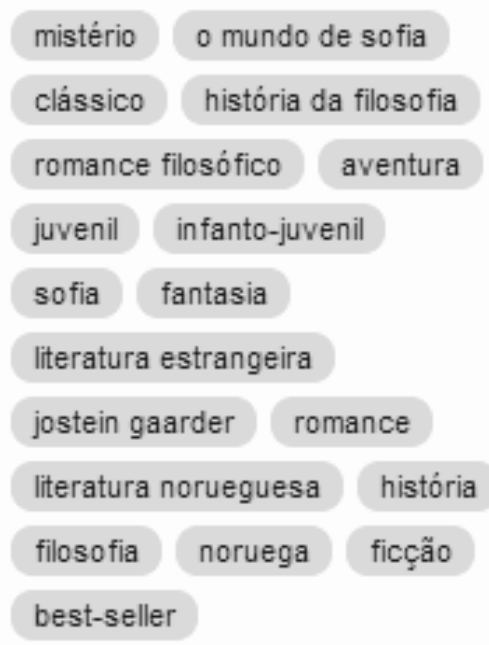

Fonte: Skoob (2013).

Em posse das tags mais populares, foram buscadas possíveis variações em sua grafia, a fim de verificar se há discrepância entre os termos utilizados para etiquetagem. Foi possível perceber que existe discrepância na grafia de algumas tags, ou seja, termos que representam os mesmos conceitos, porém escritos de maneiras diferentes (Quadro 1). 
Quadro 1 - Discrepância das tags mais populares atribuídas ao livro.

\begin{tabular}{|c|c|c|c|c|c|}
\hline Tag popular & Ocorrências & Variação & Ocorrências & Variação & Ocorrências \\
\hline aventura & 1878 & aventuras & 41 & -- & -- \\
\hline best seller & 53 & best-seller & 816 & best-seler & 1 \\
\hline clássico & 1273 & clássicos & 856 & -- & -- \\
\hline fantasia & 1522 & fantasias & 2 & -- & -- \\
\hline $\begin{array}{l}\text { infanto- } \\
\text { juvenil }\end{array}$ & 1163 & $\begin{array}{l}\text { infanto- } \\
\text { juvenis }\end{array}$ & 3 & $\begin{array}{l}\text { infanto } \\
\text { juvenil }\end{array}$ & 266 \\
\hline juvenil & 1652 & juvenis & 8 & -- & -- \\
\hline mistério & 739 & mistérios & 24 & -- & -- \\
\hline romance & 8805 & romances & 99 & -- & -- \\
\hline
\end{tabular}

Fonte: Elaborado pelos autores.

A maior discrepância encontrada entre as tags foi referente ao número (singular e plural), o que não ocorreu apenas na tag 'best-seller'. Percebeu-se que as tags com maior ocorrência aparecem grafadas no singular, o que indica uma preferência do leitor. Por exemplo, a tag 'aventura' possui 1878 obras indexadas, enquanto sua variação 'aventuras' possui apenas 41 . Note-se, também, a inconsistência no uso de hífen em 'infanto-juvenil' e 'infanto juvenis' e 'best seller' e 'bestseller'. Nesse último caso, onde também aparece a tag 'best-seler', os erros de grafia podem ser justificados por se tratar de estrangeirismo. A inconsistência das tags é um dos principais problemas apontados no uso de folksonomias, pois a simples mudança em uma letra da palavra, proposital ou acidentalmente, acaba sendo prejudicial à recuperação do conteúdo buscado.

\subsection{Análise de Conteúdo das Resenhas dos Leitores}

Através da Análise de Conteúdo das resenhas foram levantados os conceitos mais citados pelos leitores, os quais foram posteriormente comparados às tags mais populares atribuídas ao livro. Pelo uso da Análise de Conteúdo com abordagem qualitativa os conceitos semelhantes foram agrupados em três categorias: a) Assunto; b) Gênero Textual; e c) Juízos de Valor. 


\subsubsection{A Categoria Assunto}

A categoria Assunto diz respeito à tentativa da descrição da tematicidade do livro por parte do leitor. Após a análise, percebeu-se a existência do assunto principal 'filosofia' citado nas resenhas do livro "O Mundo de Sofia". Esse conceito aparece nas resenhas como o assunto principal da trama, o fio condutor do enredo. Abaixo seguem trechos extraídos das resenhas que contém o conceito 'filosofia': "[...] ele conseguiu transformar a filosofia em um romance [...]", "[...] a grande sacada do livro é ensinar filosofia através da leitura, mesclando filosofia a uma história empolgante", "um livro muito interessante, perfeito para o primeiro contato com a filosofia".

Outras expressões reforçam o assunto, como visto em 'guia filosófico', 'história da filosofia', 'manual de filosofia' e 'ensino de filosofia', os quais foram tratados como assuntos que se encaixavam dentro do conceito 'filosofia'.

\subsubsection{A Categoria Gênero Textual}

Dois conceitos que estiveram presentes na apreciação do livro pelos leitores podem ser enquadrados como Gênero Textual: 'mistério' e 'didático'. O conceito 'mistério' diz respeito ao clima de enigma criado pelas cartas anônimas recebidas pela personagem principal, como visto em: "tive que fazer uma pausa e beber água, estava tremendo de ansiedade para saber qual seria o mistério por trás dos cartões vindos de um major no Líbano para sua filha", "[...] uma menina que não sabe nada de filosofia e misteriosamente começa a receber aulas e perguntas intrigantes [...]" e "o professor demonstra conhecer o mistério por trás dos cartões-postais, mas segura a informação até quase o fim do curso (o que, confesso, foi o que me segurou pra não desistir do livro logo no começo)".

Apesar de os skoobers não afirmarem que o livro é uma narrativa de mistério, tal como um romance de suspense, os leitores enfatizam o mistério criado na obra como uma das suas principais características, 
aproximando o gênero do livro ao gênero das narrativas de mistério. Partindo das etiquetas e da apreciação crítica dos leitores, pode-se afirmar que o livro poderia ser descrito como uma narrativa de mistério, o que vai contra a descrição tradicional atribuída por um bibliotecário, que provavelmente $o$ classificaria seu gênero apenas como romance/ficção.

Outro conceito que se aproxima da descrição de gênero textual associa o livro ao seu caráter didático. Pode-se afirmar que os leitores recomendam o livro por se tratar de um material que, além de literário, é educativo, através de descrições que se aproximam ao que dentro da representação temática conhecemos como subdivisão de forma. Assim, encontramos expressões que descrevem o livro como "manual", "guia filosófico", "didático", "extremamente didático" e "proveitoso em relação a seu conteúdo", referindo-se ao conteúdo como material usado para estudo e aprendizado de filosofia.

Uma leitora compara as aulas de filosofia da faculdade ao conteúdo do livro: "já tive aulas de filosofia na faculdade e mesmo tendo gostado, absorvi muito pouco do que estudei (por pura imaturidade). Como leiga, achei o livro de Jostein Gaarder extremamente didático [...]".

Também são ressaltadas vantagens do livro em comparação ao ensino formal de filosofia nas escolas, como em: "o livro the proporciona conhecimentos que não se aprende nas escolas, infelizmente", "[...] recomendo o livro para quem está estudando filosofia e sociologia pois será de grande valia para aumentar o conhecimento [...]" e "esse livro faz você se apaixonar pela filosofia, e recomendaria muito ele, apesar de haver filosofia na escola, nada é comparado a essa história. :)". Dessa forma, alguns leitores consideram o livro mais proveitoso para o ensino da filosofia do que o próprio ensino formal, como visto abaixo:

$\mathrm{Na}$ condição de leitora e aprendiz, me (sic) identifiquei com a Sofia porque não acredito no ensino de filosofia que é aplicado nas escolas brasileiras, sendo assim o 
livro explica, de maneira básica, mas também instiga a procurar mais sobre o assunto. Gostei bastante dos capítulos que são sobre um filósofo em particular e indico principalmente a alunos do ensino médio que já tiveram contato com filosofia na escola ou para aqueles que não tem conhecimento nenhum da disciplina.

\subsubsection{A Categoria Juízos de Valor}

$\mathrm{Na}$ categoria Juízos de Valor, encontramos conceitos que expressam opiniões referentes ao material analisado. Essas opiniões podem ser divididas em elogios e críticas e mostram a posição pessoal do leitor em relação ao conteúdo do livro. Ao recomendar ou não o livro, o leitor, obviamente, o faz externalizando os sentimentos despertos durante a leitura. Notam-se opiniões totalmente contrárias; por um lado temos elogios feitos por leitores que têm na obra seu livro predileto ou um dos preferidos e, de outro lado, aqueles que não a apreciam.

Quanto aos elogios, vemos recomendações expressas em palavras e frases como: "incrível", "intrigante", "emocionante", "perfeito", "encantador", "fascinante", "excelente", "mágico", "brilhante”, "leitura obrigatória", "o melhor livro", etc.

Isso pode ser notado na fala de alguns leitores como em: "acabei de ler as últimas palavras de o mundo de Sofia. Li os últimos capítulos num fôlego só de tão incrível, intrigante e emocionante.", "uma obra fantástica e mágica", "deveria ser leitura obrigatória para todos os adolescentes" e "definitivamente, um livro entrou na lista dos meus favoritos de todos os tempos".

Quanto às críticas, as opiniões negativas referentes ao conteúdo do livro o descrevem como: "chatice", "chato", "cansativo", "complexo", "pesado", "entediante" e "matéria complexa". Os trechos a seguir dão ideia das opiniões negativas dos leitores: "não aguentei a chatice e tive que abandoná-lo. Nota mínima!", "os filósofos de plantão que me perdoem, mas que livro chato" e "o tema é muito interessante, mas o livro é muito entediante. enfim... desertei. =/". 
O uso de smileys ainda colabora na afirmação dos juízos de valor destacados pelos leitores, como $=/$ e : ).

\subsubsection{Comparando Tags e Resenhas}

Após a análise das categorias, as 19 tags populares do livro foram comparadas às categorias levantadas na etapa da Análise de Conteúdo.

Dentre os conceitos levantados durante a análise das resenhas, apenas 'mistério' e 'filosofia' aparecem entre as tags atribuídas pelos usuários do Skoob. Podemos dizer que as tags 'filosofia', 'história da filosofia' e 'romance filosófico' foram atribuídas na tentativa de descrever o assunto do livro e têm no ser cerne um mesmo conceito fundamental encontrado nas resenhas: filosofia.

Apesar de o livro tratar da história da filosofia desde seus primórdios, nenhum conceito específico sobre o assunto foi ressaltado pelos leitores nem nas tags nem nas resenhas. Alguns leitores apenas citaram conceitos ou autores preferidos da filosofia.

'Romance filosófico', além de se referir a Assunto, também faz referência ao Gênero Textual, assim como as tags 'mistério', 'aventura', 'fantasia', 'romance', 'literatura estrangeira', 'literatura norueguesa', 'ficção', 'clássico', 'juvenil' e 'infanto-juvenil'; entretanto, apenas o conceito 'mistério' foi ressaltado nas resenhas. Assim, das 19 tags atribuídas ao livro, 10 fazem referência ao gênero textual. Isso indica que o leitor também pode ter mais facilidade para descrever o gênero do que para representar a tematicidade do livro.

Chama a atenção que, nas resenhas, alguns leitores o descrevem com conceitos que o aproximam do gênero instrucional, como "didático", "manual" e "guia", já na etiquetagem salientam gêneros ficcionais. Isso pode ser explicado pelo fato de que, ao fazerem a resenha, expressam sua opinião quanto ao livro, já quando atribuem tags, preocupam-se mais em descrevê-lo tentando ser mais precisos quanto ao gênero. Dito de outra maneira, caso a obra se tratasse de um 
livro didático, isso deveria aparecer entre as tags, entretanto, seu caráter didático é mais um atributo dado pelo leitor para agregar valor ao livro do que efetivamente para descrever gênero ou forma.

A tag 'best-seller' não apareceu nas resenhas, pois nenhum dos leitores ressaltou as qualidades do livro a partir de sua grande quantidade de vendas. Esse conceito diz respeito à vendagem do livro, não podendo ser associado a nenhuma das categorias levantadas durante a Análise de Conteúdo.

$\mathrm{Na}$ lista de tags populares também encontramos 'Jostein Gaarder', 'O Mundo de Sofia' e 'Noruega', os quais revelam a preocupação dos leitores em descrever as características extrínsecas da obra (respectivamente autor, título e local), e não o seu conteúdo, o que também acontece nas resenhas. Já a tag 'Sofia' não se refere nem à descrição física e nem à temática, mas podemos afirmar que essa se aproxima mais da descrição do conteúdo, por se tratar da personagem. Pode-se inferir que a 'Sofia' não diz respeito ao conceito Sophia oriundo da filosofia; pois nas resenhas esse conceito foi citado por um único skoober. Pode-se concluir, através da análise das 30 resenhas, que a associação entre Sofia e Sophia é do conhecimento de poucos leitores.

\section{CONSIDERAÇÕES FINAIS}

Através da rede social brasileira Skoob, fizemos uma análise das tags 'públicas' usadas para descrever e encontrar os livros no site, uma vez que a etiquetagem representa o comportamento do leitor referente à indexação social, demonstrando sua maneira de classificar os livros através de conceitos atribuídos livremente aos recursos.

O fenômeno de indexação social, também conhecido como folksonomia, cunhado por Vander Wal em 2004, tem como vantagem recuperar e compartilhar o conhecimento com estrutura mais flexível e fácil de usar através de etiquetas ou tags na internet, porém o mesmo ato possui desvantagens como incoerências, erros de grafia e 
problemas no uso de significados genéricos ou específicos (GOUVÊA; $\mathrm{LOH}, 2007)$. Explorando o uso da indexação social na rede Skoob, tendo em conta a análise dos conceitos utilizados nas tags e nas resenhas inseridas pelos usuários para descrever o conteúdo do livro "O Mundo de Sofia: romance da história da filosofia", pudemos verificar que a discrepância de grafia nas tags, como citada por Gouvêa e Loh (2007), foi muito presente na etiquetagem analisada, principalmente quanto ao número singular e plural, o que indica uma preferência dos leitores pelo uso de tags no singular.

Pela análise de um grupo de 30 resenhas, pudemos não apenas entrar em contato como opiniões e pontos de vista dos diferentes leitores, mas verificar que seus textos críticos acabam por ajudar a descrever o livro resenhado. Entretanto, percebeu-se que os conceitos presentes em ambas as descrições são diferentes: ao etiquetar, o usuário deu preferência por descrever o gênero do livro, seguido de dados de descrição física, já ao resenhar, o livro foi descrito pelas qualidades ou defeitos de acordo com os juízos de valor dos leitores.

Como o site Skoob não usa o sistema de nuvem de tags, o qual indica graficamente as palavras mais citadas, não se sabe, dentre as etiquetas mais populares atribuídas ao livro, quais as mais frequentes, o que permitiria criar um ranking visualmente hierarquizado.

Percebemos, na atribuição de tags 'públicas', uma atitude altruísta do leitor, tal como citado por Cañada (2006), uma vez que os conceitos mais populares são mais descritivos, conhecidos e aceitos. Entretanto, isso se deve ao fato de que o Skoob permite a inserção de dois tipos de tag: as tags de 'estante', cuja função é organizar a área pessoal do skoober, e as tags 'públicas', cujo objetivo é justamente ajudar na descrição das obras. Como as tags de 'estante' são apenas para uso pessoal, não pudemos ter acesso a elas; um estudo baseado nessas poderia trazer dados diferentes, revelando uma posição mais pessoal dos leitores ao indexarem os livros. 
O estudo exploratório da indexação social de obras literárias mostrou-se uma boa fonte de análise da garantia do usuário; assim, ressaltamos a necessidade de estudos que aprofundem a questão do uso do vocabulário dos não especialistas para a análise e a representação de obras literárias.

\section{REFERÊNCIAS}

BARDIN, Laurence. Análise de conteúdo. Tradução de Luis Antero Reto. São Paulo: Edições 70, 1977.

CAÑADA, Javier. Tipologías y estilos en el etiquetado social. 2006. Disponível em: <http://www.terremoto.net/tipologias-y-estlos-en-eletiquetado-social/>. Acesso em: 20 out. 2013.

CATARINO, Maria Elisabete; BAPTISTA, Ana Alice. Folksonomias: características das etiquetas na descrição de recursos da web.

Informação \& Informação, Londrina, v. 14, n. esp., p. 46-67, 2009. Disponível em:

<http://www.uel.br/revistas/uel/index.php/informacao/article/view/3234>. Acesso em: 27 jul. 2013.

GOUVÊA, Cleber; LOH, Stanley. Folksonomias: identificação de padrões na seleção de tags para descrever conteúdos. RESI: Revista Eletrônica de Sistemas de Informação, Campo Largo, v. 11, n. 2, p. 1-8, 2007. Disponível em:

<http://revistas.facecla.com.br/index.php/reinfo/article/view/214/118>. Acesso em: 27 set. 2013.

GUEDES, Roger de Miranda; DIAS, Eduardo José Wense. Indexação social: abordagem conceitual. Revista ACB: Biblioteconomia em Santa Catarina, Florianópolis, v. 15, n. 1, p. 39-53, jan./jun. 2010. Disponível em: <http://revista.acbsc.org.br/racb/article/view/686>. Acesso em: 27 fev. 2013.

GUIMARÃES, José Augusto Chaves; MORAES, João Batista Ernesto de; GUARIDO, Maura Duarte Moreira. Análisis documental de contenido de textos narrativos: bases epistemológicas y perspectivas metodológicas. Ibersid: Revista de Sistemas de Información y Documentación, Zaragoza, v. 1, p. 93-99, 2007. Disponível em: <http://ibersid.eu/ojs/index.php/ibersid/article/viewArticle/3267>. Acesso em: 14 nov. 2013. 
MORAES, João Batista Ernesto. Perspectivas metodológicas para a identificação do aboutness em textos narrativos de ficção. Scire, Zaragoza, v. 18, n. 2, p. 57-66, 2012. Disponível em:

<ibersid.eu/ojs/index.php/scire/article/download/3965/3707>. Acesso em: 14 nov. 2013.

SANTOS, Hercules Pimenta. Etiquetagem e folksonomia: o usuário e sua motivação para organizar e compartilhar informação na Web 2.0.

Perspectivas em Ciência da Informação, Belo Horizonte, v. 18, n. 2, p. 91-104, abr./jun. 2013. Disponível em: $<$ http://portaldeperiodicos.eci.ufmg.br/index.php/pci/article/view/1617>. Acesso em: 6 jun. 2013.

SKOOB. Quem somos? Disponível em: <http://www.skoob.com.br/inicio/quem_somos>. Acesso em 16 jun. 2013.

VANDER WAL, Thomas. Folksonomy definition and Wikipedia. 2005. Disponível em: $<$ http://www.vanderwal.net/random/entrysel.php?blog=1750>. Acesso em: 2 set. 2013.

VANDER WAL, Thomas. Folksonomy: Brasilian research [mensagem pessoal]. Mensagem recebida por <marinabenetti93@gmail.com> em 3 out. 2013.

\title{
Title
}

Social indexing at skoob: the description of the book 'Sophie's world' from tags and reviews

\begin{abstract}
Introduction: Skoob is a Brazilian social network based on the exchange of information of books and magazines, which allows the user, or skoobers, to insert of tags for organizing their personal bookshelves, as well as the sharing of public resources description. The analysis of the labeling of literary books is an indicative of the behavior of readers across the social activity index.

Objective: To explore the social indexing done at Skoob, in order to examine the concepts used in tags, comparing them to the concepts present in reviews written by readers.

Metodology: The book selected was 'Sophie's World: a novel about the history of philosophy' by Jostein Gaarder. First of all, we raised the discrepancy of the most popular tags assigned to the book. Then, through the content analysis with qualitative approach, we analyzed 30 reviews in order to raise the concepts in critical appreciation from readers. Finally, a comparison was made between the concepts of tags and reviews.
\end{abstract}


Results: There was a variance between the tags that doesn't refer to the number (singular or plural). The concepts raised in the reviews were grouped into three categories: a) Subject, b) Textual Genre, and c) Value Judgments. The concepts presented in the tags and the book reviews generally were different.

Conclusion: It was possible, by analysing the reviews, to deep the understanding of some concepts found in the tags. However, among the concepts cited in the reviews only philosophy and mystery were present in the most of the popular tags.

Keywords: Folksonomies. Literature. Social network. Content analysis.

\section{Titulo}

Indización social en skoob: la descripción del libro 'el mundo de Sofía' a partir de tags y reseñas

\section{Resumen}

Introducción: El Skoob es una red social brasileña basada en el intercambio de información sobre libros y revistas, lo que permite que el usuario, o skoobers, coloque etiquetas para organizar sus bibliotecas personales, así como el intercambio de la descripción de los recursos públicos. El análisis del etiquetado de los libros literarios es indicativo del comportamiento de los lectores de todo el índice de actividad social.

Objetivo: Explorar la indexación social hecha en Skoob, con el fin de examinar los conceptos utilizados en las etiquetas, y así compararlos con los conceptos presentes en las reseñas escritas por los lectores.

Metodología: Fue seleccionado el libro 'El mundo de Sofía' de Jostein Gaarder. En primer lugar, hemos planteado la discrepancia de las etiquetas más populares asignados al libro. Entonces, a través del análisis de contenido con enfoque cualitativo, se analizaron 30 críticas con el fin de elevar los conceptos de apreciación crítica de los lectores. Por último, se realizó una comparación entre los conceptos de etiquetas y comentarios.

Resultados: Hubo una discrepancia entre las etiquetas que no se refiere al número (singular o plural). Los conceptos planteados en los exámenes fueron agrupados en tres categorías: a) Sujetos, b) Género Textual, y c) Juicios de Valor. Los conceptos presentados en las etiquetas y las reseñas de libros en general eran diferentes.

Conclusión: Fue posible, mediante el análisis de las reseñas, a lo profundo de la comprensión de algunos de los conceptos que se encuentran en las etiquetas. Sin embargo, entre los conceptos citados en los comentarios sólo la filosofía y el misterio están presentes en la mayoría de las etiquetas más populares.

Palabras clave: Folksonomias. Literatura. Red social. Análisis de contenido.

Recebido em: 01.12.2013

Aceito em: 18.02 .2016 